\title{
Zinc Enzymes in Commercial Pronase-P. Further Characterization of the Heterogeneity of the Proteolytic
} Enzymes of the K-1 Strain of Streptomyces griseus

\author{
BO LÖFQVIST
}

Biochemistry 1, Chemical Center, University of Lund, P.0.B. 740, S-220 07 Lund 7, Sweden

Pronase has been shown to contain both zinc endopeptidases and zinc aminopeptidases. The zinc atom could be reversibly removed by pentaethylenehexamine in presence of 30 $\mathrm{mM} \mathrm{Ca} \mathrm{Ca}^{2+}$ A considerable heterogeneity was found within both groups of enzymes by separation on gel electrophoresis and gel chromatography, and it was concluded that limited proteolysis had occurred during the fermentation or isolation procedures of Pronase. Consequently it is uncertain to which extent the zinc enzymes present in Pronase are identical to the ones produced by the actinomycete. A minimum number of genuine enzymes, which could account for the observed heterogeneity, was suggested. This included two zinc endopeptidases and two zinc exopeptidases. In addition to these enzymes it was concluded that the Kl Strain of Streptomyces also produced one carboxypeptidase and four different serine endopeptidases. The catalytic mechanism of the carboxypeptidase was not conclusively elucidated. It was, however, proposed to be a metallo enzyme with a most firmly bound prosthetic ion.

Pronase, which was first isolated and characterized as a homogeneous extracellular enzyme produced by Streptomyces griseus Strain K1,1 has been shown to be an extremely complex mixture of proteolytically active components. ${ }^{2-4}$ Due to substrate analysis evidence has also been presented indicating that Pronase contains various groups of proteinases, namely neutral and alkaline proteases, aminopeptidases, and carboxypeptidases., ,4-6 $^{4}$ The heterogeneity of the alkaline proteinases is well established and four different enzymes have been identified. One of these is described as subtilisin-like,

Acta Chem. Scand. B 28 (1974) No. 9 while two show similarities to the mammalian proteinases from pancreas. ${ }^{7,8}$ These three alkaline proteinases are thus found to be serine enzymes. The fourth component with alkaline proteinase activity has so far only been found in one particular batch of Pronase-P and has not been further characterized. Further one serine proteinase, described as trypsin-like, is present in Pronase, which hence is found to contain four or maybe five serine proteinases.

The other groups of proteinases in Pronase are less well-known and have so far not been subject to any extensive characterization. Narahashi et al..$^{10}$ observed that EDTA inhibits the amino- and carboxypeptidase activity as well as $65 \%$ of the neutral proteinase activity. Although $\mathrm{Ca}^{2+}$ ions are known to be essential for the stability of Pronase, 11 it is not clear whether the inactivation caused by EDTA is due to destabilization of the tertiary structures of Pronase components by removal of the $\mathrm{Ca}^{2+}$ ions ${ }^{12}$ or to inhibition of enzymatic activity of metallo enzymes by removal of prosthetic metal ions.

In a preceding paper ${ }^{13}$ Löfqvist and Klevhag described the separation of Pronase into seven enzymatically active peaks by chromatography on Sephadex G-75 Superfine, as well as the heterogeneity of each peak on polyacrylamide gel electrophoresis. In this paper these different Pronase peaks are characterized further with respect to their metal ion requirement and enzymatic activity in order to elucidate the nature of the observed heterogeneity of Pronase. 


\section{EXPERIMENTAL}

Materials. Enzyme: Pronase-P (lot No. 592045 , in the preceding paper ${ }^{13}$ abbreviated. Pronase IV) was obtained from the Kaken Chemical Company, Tokyo.

Inhibitors: Diisopropylfluorophosphate, pentaethylenehexamine, and 1,10-phenantrolin were products of Fluka AG.

Enzyme substrates: Casein of Hammarsten grade and glutaryl-L-phenylalanine-p-nitroanilide were obtained from Merck AG, $L$ leucine- $\beta$-naphthylamide. $\mathrm{HCl}$ and $N$-benzoyl-

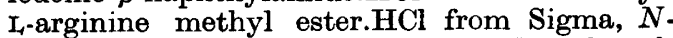
carbobenzoxy-L-glycyl-L-leucine and 4-phenylazobenzyloxycarbonyl-L-prolyl-L-leucyl-L,-gly-

cyl-1-prolyl-D arginine. $2 \mathrm{H}_{2} \mathrm{O}$ from Fluka $\mathrm{AG}$. All other low molecular weight substrates were purchased from Cyclo Chemical Co.

Separation methods. Preparative gel chromatography was performed on a $2.5 \times 90 \mathrm{~cm}$ bed of Sephadex G-75 Superfine prepared according to Löfqvist and Klevhag. ${ }^{13}$ The protein fractions were stored at $4^{\circ} \mathrm{C}$.

Preparative polyacrylamide gel electrophoresis: $1.4 \mathrm{mg}$ Pronase or $100 \mu \mathrm{l}$ of the eluate in peak $\mathrm{F}$ from the gel chromatography separation was applied in sucrose stabilized $0.38 \mathrm{M}$ boric acid $-0.01 \mathrm{M} \mathrm{CaO}$ buffer, $\mathrm{pH} 6.8$, to preflushed $1 \times 10 \mathrm{~cm}$ gels and analyzed for enzymatic activity according to Löfqvist and Sjöberg."

Analytical gel chromatography: A $2.5+90$ cm Sephadex G-75 Superfine bed was used for analytical purposes by applying only $1 \mathrm{mg}$ Pronase. An improved resolution was thereby obtained, but due to the low amount of $A_{280}$ $\mathrm{nm}$ absorbing material the eluted Pronase components had to be identified by their enzymatic activity.

Determination of metal content. The metal content in Pronase was determined by atomic absorption spectrometry of suitable amounts dissolved in nitric and perchloric acid. Zinc was also determined directly in the eluted fractions from the gel chromatography column. Corrections for blanc values were made.

Inhibition procedures. Inhibition by both DFP* and penten was, unless otherwise specified, carried out directly on the eluate by incubation for $30 \mathrm{~min}$ in presence of at least $100 \mathrm{~mol}$ excess of the inhibitor. The zinc enzymes were reactivated by addition of

* Non-standard abbreviations. Pentaethylenehexamine, penten; diisopropylfluorophosphate, DFP; Lleucine- $\boldsymbol{\beta}$-naphthylamide.HCl, LNA; $N$-benzoyl-Larginine methyl ester, BAME; 4-phenylazobenzyloxycarbonyl-L-prolyl-L,-leucyl-L- glycyl-L,-prolyl-Darginine, collagenase substrate $A$; glutaryl-L-phenylalanine-p-nitroanilide, GPNA; Acetyl, Ac; carbobenzoxy, CBZ; standard buffer, $0.03 \mathrm{M}$ borate buffer, pH 7.5, 0.03 $\mathrm{M}$ in $\mathrm{CaCl}_{2}$ and containing $0.02 \% \mathrm{NaN}_{3}$.
$\mathrm{ZnCl}_{2}$ in $20 \%$ excess amounts compared to the concentration of penten. In case of the carboxypeptidases $5 \mathrm{ml}$ of the fractions from the gel chromatography column were dialyzed towards $1000 \mathrm{ml}$ of $5 \times 10^{-4} \mathrm{M}$ EDTA or penten in standard buffer for $24 \mathrm{~h}$ at $4^{\circ} \mathrm{C}$.

Determination of enzymatic activity. Enzymatic activity towards casein, LNA and BAME was determined as described in the preceding paper. ${ }^{18}$ Activity towards GPNA was measured at $40{ }^{\circ} \mathrm{C}$ according to the method of Erlanger et al. ${ }^{14}$ as described by Bauer and Löfqvist. ${ }^{15}$ Collagenolytic activity was determined at $40{ }^{\circ} \mathrm{C}$ according to the method of Wünsch and Heidrich. ${ }^{16}$ Enzymatic activity towards all other substrates was assayed at $40^{\circ} \mathrm{C}$ by the ninhydrin method. ${ }^{17}$

\section{RESULTS}

In order to examine if other metal ions than $\mathrm{Ca}^{2+}$ were present in Pronase an analysis using atomic absorption spectrometry was performed. The results obtained are collected in Table 1. The only metal ions found in sub. stantial amounts except calcium were zinc and magnesium. Other ions like $\mathrm{Co}, \mathrm{Cu}$, and Cd were found only in trace amounts and were assumed insignificant for the enzymatic activity of the Pronase components.

Since no requirement for magnesium ions has been reported for proteolytic enzymes, these ions in Pronase were regarded as a residue from the culture medium of the actinomycete and their functional role was thus not further investigated. Zinc, however, has been observed as prosthetic metal ion in several proteinases of microbial origin ${ }^{18,19}$ Assuming an average molecular weight of 30000 dalton ${ }^{13}$ for the Pronase components, the zinc content corresponded to one zinc atom for every fourth protein molecule. It was thus of interest to further investigate the role of zinc in Pronase.

Table 1. The amounts of metal ions (in ppm) found in commercial Pronase-P.

\begin{tabular}{lr}
\hline Calcium & 99000 \\
Magnesium & $\mathbf{7 2 0}$ \\
Zinc & $\mathbf{3 1 0}$ \\
Cobalt & $\mathbf{8}$ \\
Nickel & $\mathbf{9}$ \\
Manganese & 12 \\
Cadmium & $\mathbf{2}$ \\
Copper & 23 \\
Lead & 12 \\
\hline
\end{tabular}

Acta Chem. Scand. B 28 (1974) No. 9 


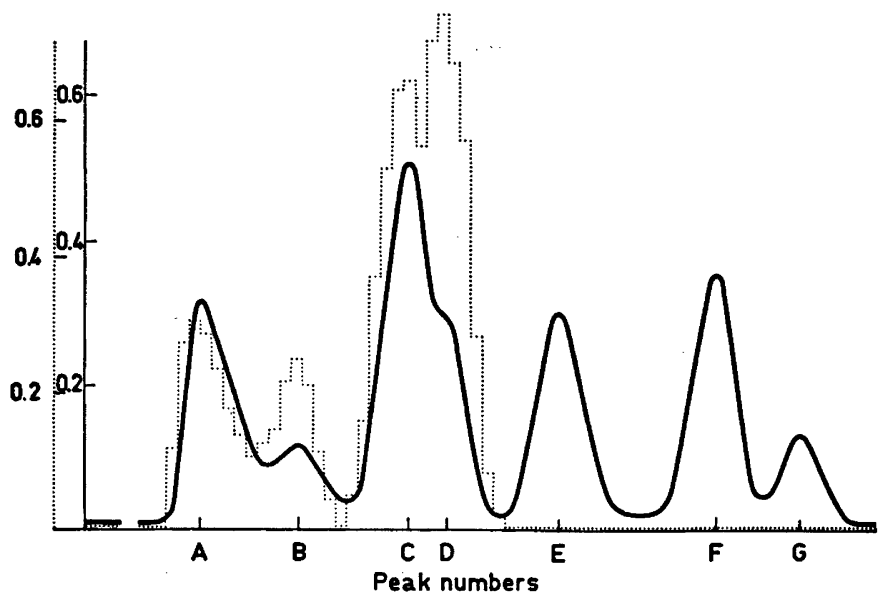

Fig. 1. Elution diagram showing the zinc content found in different peaks of Pronase-P separated by gel chromatography on a $2.5 \times 90 \mathrm{~cm}$ Sephadex G-75 Superfine bed. -, Absorbance at $280 \mathrm{~nm}$; $\cdots, \mathrm{ppm} \mathrm{Zn} / \mathrm{ml}$.

This has to be done in presence of calcium ions, since these were reported to stabilize the Pronase components. Consequently EDTA, which chelates both zine and calcium ions, could not be used to remove the zinc ions. The addition of $10^{2}$ molar excess of 1,10 phenantrolin, a commonly used chelating agent for zine, gave only a slight inhibition of the activity of Pronase. Pentaethylenehexamine (penten) on the other hand was found to be more potent as a chelating agent for zinc.

Pronase (1 $\mathrm{mg} / \mathrm{ml}$ ) dissolved in a buffer containing $30 \mathrm{mM} \mathrm{Ca}{ }^{2+}$ was treated with $1 \mathrm{mM}$ penten and $1 \mathrm{mM}$ DFP. After incubation for half an hour at room temperature no residual activity towards LNA, BAME or casein at neutral or alkaline $\mathrm{pH}$ could be observed. By addition of zinc to a final concentration of $1.2 \mathrm{mM}$ approximately $65 \%$ of the activity towards casein when analyzed at pH 7.5 and the leucineaminopeptidase activity were restored. No activity towards BAME or casein at $\mathrm{pH} 10$ could, however, be detected under these conditions. These inhibition studies indicated that Pronase contained enzymes with two entirely different types of catalytic mechanisms, namely zinc proteinases and serine proteinases.

In order to investigate if zinc ions were bound to various Pronase components, Pronase was separated by gel chromatography on

Acta Chem. Scand. B 28 (1974) No. 9
Sephadex G-75 Superfine, ${ }^{13}$ and each fraction was analyzed for its zinc content by atomic absorption spectrometry (Fig. 1). It is seen that zinc is bound to Pronase components eluted in the first four peaks $(A-D)$ of the elution diagram. No significant amount of zinc was detected in the remaining peaks E-G. In total, $65 \%$ of the zinc present in the Pronase-P preparation was recovered in peaks A-D. The ratio of zinc content to $A_{280}$ absorbance differed from peak to peak (Fig. 1). In peaks $A$ and $C$ the zinc content was low, around $1 \mathrm{ppm}$ per unit of $\mathrm{OD}_{\mathbf{2 8 0}} \mathrm{nm}$, while in peaks $B$ and $D$ it was around 2.5 times higher. These results thus show that there are zinc proteinases present in Pronase, and that these components are eluted in the first four peaks $(A-D)$ from the gel chromatography column.

Zinc endopeptidases. The various zinc-containing Pronase components present in peaks A-D were further investigated as to substrate specificity. Thus aliquot of the fractions collected from the separation shown in Fig. 1 were treated with DFP in order to inhibit the serine proteinases and analyzed for activity towards casein at $\mathrm{pH} 7.5$ and collagenase substrate A. Enzymatic activity towards both these substrates was found in the two peaks $A$ and $C$ (Fig. 2). A substantial tailing was found for peak $A$, but no indications for 


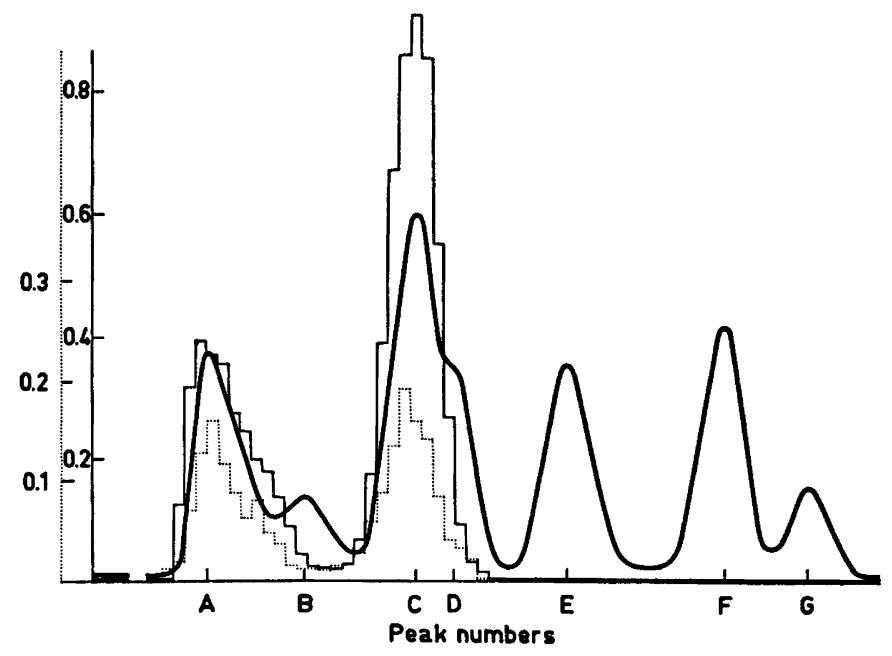

Fig. 2. Zinc endopeptidases found in Pronase-P after separation of $80 \mathrm{mg}$ by gel chromatography on a $2.5 \times 90 \mathrm{~cm}$ Sephadex G-75 Superfine bed. The enzymatic activities were measured against casein at $\mathrm{pH} 7.5$ and collagenase substrate $A$ on fractions preincubated with $1 \mathrm{mM}$ DFP for 30 min and calculated as optical density per ml eluate and minute, - , Caseinolytic activity (pH 7.5)

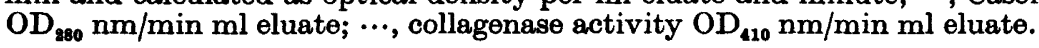

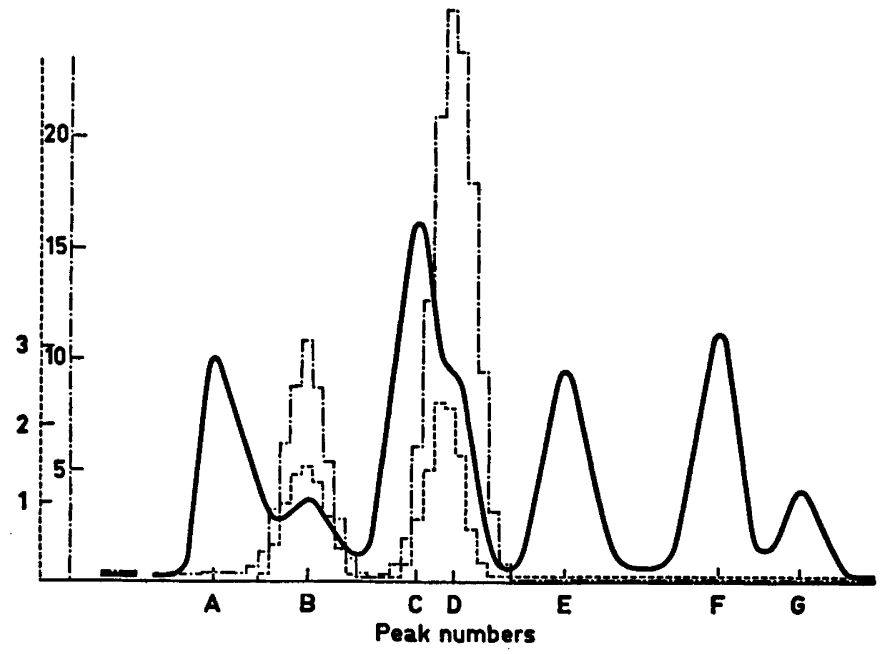

Fig. 3. Zinc aminopeptidases found in Pronase-P after separation of $80 \mathrm{mg}$ by gel chromatography on a $2.5 \times 90 \mathrm{~cm}$ Sephadex G-75 Superfine bed. The enzymatic activities were measured against LNA and pro-tyr and calculated as optical density per ml eluate and minute. - - - , LNA activity $\mathrm{OD}_{\text {sso }} \mathrm{nm} / \mathrm{min} \mathrm{ml} \mathrm{eluate;} \mathrm{...,} \mathrm{pro-tyr} \mathrm{activity} \mathrm{OD}_{570} \mathrm{~nm} / \mathrm{min} \mathrm{ml}$ eluate.

heterogeneity in substrate specificity between different Pronase components within either one of peaks $A$ and $C^{13}$ was found. Activity was also observed towards a number of other substrates, CBZ-gly-phe-NH, CBZ-gly-tyr$\mathrm{NH}_{2}, \mathrm{CBZ}$-gly-leu-NH, $\mathrm{NH}_{2}, \mathrm{CBZ}$-trp-leu- $\mathrm{NH}_{2}$, and
Ac-phe-tyr- $\mathrm{NH}_{2}$, but also these substrates failed to indicate any differences in substrate specificity between the Pronase components in each of peaks $A$ and $C$.

The DFP-treated fractions of peaks A-D were also made $1 \mathrm{mM}$ with respect to penten 
and tested for activity towards casein at pH 7.5 and collagenase substrate $A$. No residual enzymatic activity was found. The activity could, however, be completely restored by addition of zinc in excess amounts $(1.2 \mathrm{mM})$. It was thus concluded that Pronase components eluted in peak $A$ and $C$ could be classified as zinc endopeptidases with neutral proteinase and collagenase activity.

Peaks $\mathbf{A}$ and $\mathbf{C}$ were found to contain low amounts of zinc compared to peaks $B$ and $D$ (Fig. 1), and it was questioned if the zinc endopeptidases had been depleted of zinc during the separation of Pronase on the gel chromatography column. This, however, did not seem to be the case to any substantial degree, since the enzymatic activity measured for the endopeptidases after reactivation with excess amounts of zinc was only 5-10\% higher than that observed prior to the penten inhibition.

Zinc aminopeptidases. Each fraction from the elution diagram shown in Fig. 1 was also tested for aminopeptidase activity using LNA and pro-tyr as substrates. The observed activities (Fig. 3) show that all the aminopeptidase activity in Pronase was present in peaks $B$ and D. A complete inactivation of the LNA active fractions was observed by the ad. dition of penten to a final concentration of $1 \mathrm{mM}$. The activity was restored by addition of excess amounts (1.2 mM) of zinc, as was the case for the zinc endopeptidases. Consequently it can be concluded that the aminopeptidases in Pronase are zinc exopeptidases.

Carboxypeptidases. A third category of enzymes found in Pronase are the carboxypeptidases, which have been described to have a substrate specificity similar to the mammalian carboxypeptidase A (E.C. 3.4.2.1) ${ }^{2}$ using CBZgly-leu as substrate. Carboxypeptidase activity was found in peaks $A, C, D$ and in the region between peaks $\mathrm{D}$ and $\mathrm{E}$ (Fig. 4). The activity in peaks $A$ and $C$ showed exactly the same elution profile as the zinc endopeptidases. Thus CBZ-gly-leu did not seem to be completely selective as a substrate in searching for carboxypeptidases in Pronase. The activity found in peak $D$ and in the region between peak $\mathrm{D}$ and $\mathrm{E}$, however, did not show any endopeptidase activity and thus seemed to correspond to components with true carboxypeptidase activity. Other substrates like CBZglu-tyr, CBZ-gly-phe and Ac-phe-tyr were also hydrolyzed by these carboxypeptidases.

In contrast to the zinc endopeptidases and the aminopeptidases the carboxypeptidase activity in peak $D$ and in the region between

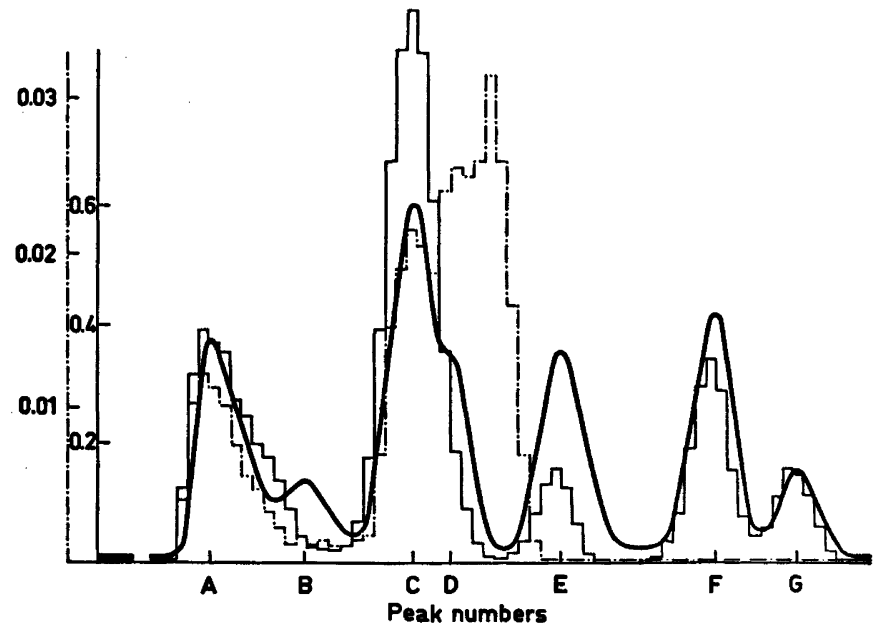

Fig. 4. Carboxypeptidase activity against CBZ-gly-leu and caseinolytic activity at pH 7.5 found in Pronase after separation of $80 \mathrm{mg}$ by gel chromatography on a $2.5 \times 90 \mathrm{~cm}$ Sephadex G-75 Superfine bed. The enzymatic activities are calculated as optical density per ml eluate and minute. -, Caseinolytic activity ( $\mathrm{pH}$ 7.5) $\mathrm{OD}_{280} \mathrm{~nm} \mathrm{~min} \mathrm{ml}$ eluate; - - , CBZ-gly-leu activity $\mathrm{OD}_{570}$ $\mathrm{nm} / \mathrm{min} \mathrm{ml}$ eluate.

Acta Chem. Scand. B 28 (1974) No. 9 


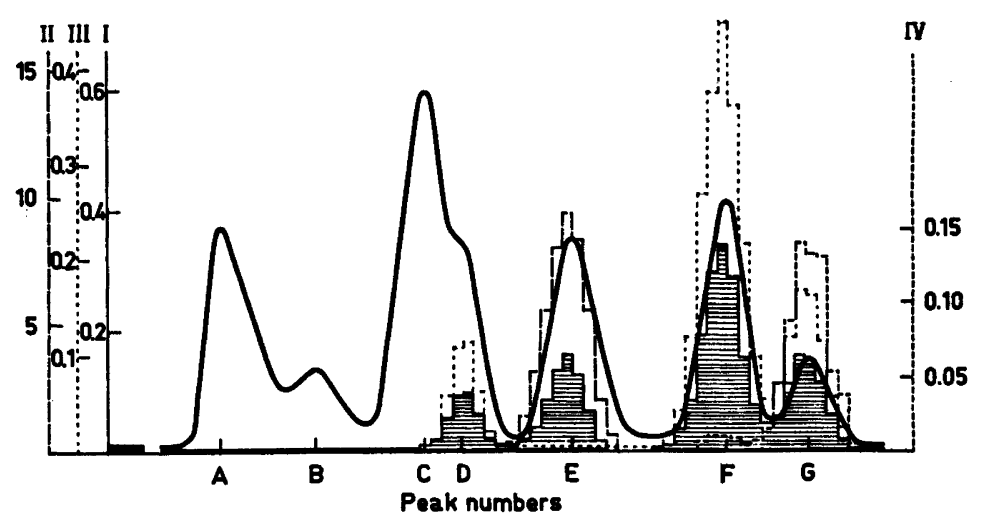

Fig. 5. Serine proteinases found in Pronase-P after separation of $80 \mathrm{mg}$ by gel chromatography on a $2.5 \times 90 \mathrm{~cm}$ Sephadex G-75 Superfine bed. The enzymatic activities were measured against casein at $\mathrm{pH} 7.5$ and 10, BAME and GPNA on fractions preincubated with $1 \mathrm{mM}$ penten for $30 \mathrm{~min}$ and calculated as optical density per ml eluate and minute. I, Caseinolytic activity (pH 7.5) $\mathrm{OD}_{280} \mathrm{~nm} / \mathrm{min} \mathrm{ml}$ eluate; II, BAME activity $\mathrm{OD}_{258} \mathrm{~nm} / \mathrm{min} \mathrm{ml}$ eluate; III, caseinolytic activity $\left(\mathrm{pH}\right.$ 10) $\mathrm{OD}_{280} \mathrm{~nm} / \mathrm{min} \mathrm{ml}$ eluate; IV, GPNA activity $\mathrm{OD}_{\mathbf{4 1 0}} \mathrm{nm} / \mathrm{min}$ ml eluate. Roman numerals refer to the various enzymatic activities.

peaks $\mathrm{D}$ and $\mathrm{E}$ was not inhibited by $1 \mathrm{mM}$ penten. Not even $10 \mathrm{mM}$ penten followed by filtration on Sephadex G-25 or dialysis towards $0.5 \mathrm{mM}$ penten or EDTA had any effect on the activity. Nor did $1 \mathrm{mM}$ DFP show any effect on the carboxypeptidase activity. When the fractions were made $1 \mathrm{mM}$ with respect to $\mathrm{HgCl}_{2}$, however, the components were irreversibly inactivated.

Since the total amount of carboxypeptidase activity in the investigated batch of Pronase-P was found to be much lower than could be expected from the results of Narahashi et al.,2 several other batches of Pronase were also analyzed for this activity. Large variations between different batches were found, and the Pronase I 4,18 for example contained 20 times more activity than the batch used in this in. vestigation. The carboxypeptidase in Pronase thus seemed to be rather instable during the isolation procedure used for Pronase-P.

Serine endopeptidases. Another aliquot of each of the fractions from the elution diagram shown in Fig. 1 was made $1 \mathrm{mM}$ with respect to penten to inhibit the zinc enzymes. A residual activity towards casein at neutral $\mathrm{pH}$ was found in peaks $D, E, F$, and $G$ as shown in Fig. 5. The original activity in E, F, and G was unaffected by penten. Although the residual activity in peak $D$ was found in the same fractions as the collagenase activity presented in Fig. 2. no activity was found when tested against collagenase substrate $A$ or LNA in the presence of penten.

Subsequent incubation with DFP of these fractions showing neutral proteinase activity gave a complete inactivation, and no activity towards casein at pH 7.5 or $\mathrm{pH} 10, \mathrm{BAME}$ or GPNA could be detected. This further established the presence of at least four different serine proteinases in Pronase.

Further examinations concerning the substrate specificity of the serine enzymes in peaks $D-G$ were performed. Activity towards casein at $\mathrm{pH} 10$ was found in peaks $\mathrm{D}, \mathrm{F}$, and $G$, while no such activity was found in peak E. On the other hand peak $E$ was the only peak showing activity towards BAME and thus corresponded to the trypsin-like enzyme found in Pronase.8,"

Peaks D-G were also tested towards the chymotrypsin substrate GPNA. Activity was mainly found in peak $G$, as has already been reported by Bauer and Löfqvist, ${ }^{15}$ but a small amount of activity was also present in peak $\mathrm{F}$. Minor activities towards CBZ-glu-tyr, CBZgly-phe and Ac-phe-tyr were also found in peak $F$. These activities were not inhibited by $1 \mathrm{mM}$ DFP or $1 \mathrm{mM}$ penten. Dialysis towards $0.5 \mathrm{mM}$ penten was, however, sufficient to cause an inactivation. The activities could then also be restored by the addition of excess 
amounts of $\mathrm{Zn}^{2+}$. By preparative polyacrylamide gel electrophoresis of the eluate in peak $F$ it was possible to distinguish along with the main component in band position 1 , also two minor bands in position 2 and 3. No neutral proteinase activity could be detected in these minor bands. They contained, however, all the carboxypeptidase activity found in peak $F$. It is thus likely that the weak band in position 2 observed in peak F of Pronase IV by Löfqvist and Klevhag ${ }^{13}$ is not equivalent to the alkaline proteinase found in band position 2 in Pronase $I$.

Among the substrates tested CBZ-ala-val$\mathrm{OMe}$ was found to be rather specific for the serine proteinase present in peak $D$. This enzyme was also active towards casein at $\mathrm{pH}$ 10 , which further strengthened the suggestion ${ }^{13}$ that the subtilisin-like component ${ }^{7}$ in Pronase is found in this peak.

\section{DISCUSSION}

By use of the gel chromatography separation method of Löfqvist and Klevhag ${ }^{13}$ Pronase has been found to be a mixture of mainly zinc- and serine-proteinases. The zinc enzymes are found in the first four peaks (A-D) of the elution diagram. Along with the zinc proteinases peak $D$ also contained carboxypeptidase activity as well as a serine proteinase. The additional serine proteinases were eluted in peaks $\mathrm{E}, \mathrm{F}$, and G. The zinc enzymes were according to their substrate specificity divided into endoand exopeptidases.

Zinc endopeptidases. Zinc has been found to be essential for the enzymatic activity of the endopeptidases eluted in peak $A$ and $C$ and could be exchanged reversibly in presence of $30 \mathrm{mM} \mathrm{Ca}{ }^{2+}$. It was thus concluded that these enzymes are zinc proteinases. The content of zinc corresponds to 0.8 and 0.5 zinc atoms per mol enzyme in peak $A$ and $C$, respectively, as calculated from the molecular weights $(50000$ and 28000 dalton $)^{13}$ and an assumed $\varepsilon(1 \%$, $1 \mathrm{~cm})$ at $280 \mathrm{~nm}$ of 10 . A considerable heterogeneity of the material eluted in peak $\mathbf{A}$ and $\mathrm{C}$ was found ${ }^{13}$ by analysis on polyacrylamide gel electrophoresis and in accordance with the above calculated low zinc values it was questioned to which extent the components present in peak $A$ and $C$ were active enzymes. In the earlier separation of Pronase on polyacrylamide gel electrophoresis at $\mathrm{pH} 6.8$ for $9 \mathrm{~h}^{4}$ it is, for example, observed that one of the components in peak A (Band 8) was enzymatically inactive. A separation of Pronase on preparative polyacrylamide gel electrophoresis was thus performed in order to examine, whether the various components found within peak $\mathrm{A}$ and $\mathrm{C}$ were enzymatically active. As

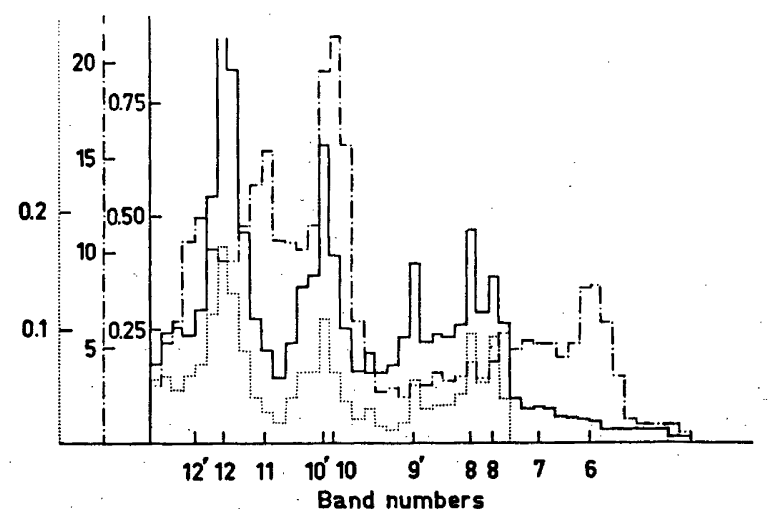

Fig. 6. Histogram showing the enzymatic activities of Pronase-P found in the different gel frac. tions of a small $(1 \times 10 \mathrm{~cm})$ preparative polyacrylamide gel after $6 \mathrm{~h}$ electrophoresis (cathodic migration) in $0.38 \mathrm{M}$ boric acid $-0.01 \mathrm{M} \mathrm{CaO}$ buffer. The gel fractions $(0.5 \mathrm{~mm}$ thick) were extracted at $\mathrm{pH} 7.5$ with standard buffer, incubated for half an hour with $1 \mathrm{mM}$ DFP and tested for activity towards casein at pH 7.5 and 10 as well as LNA. The activities found are given in optical density per ml extract and hour. Band numbers are given as suggested by Löfqvist and Sjöberg ${ }^{4}$ from the staining found in a duplicate run. -, Caseinolytic activity (pH 7.5) $\mathrm{OD}_{280}$ $\mathrm{nm} / \mathrm{h} \mathrm{ml}$ eluate; ..., collagenase activity $O D_{410} \mathrm{~nm} / \mathrm{h} \mathrm{ml}$ eluate; - - , LNA activity $\mathrm{OD}_{560} \mathrm{~nm} / \mathrm{h}$ ml eluate.

Acta Chem. Scand. B 28 (1974) No. 9 


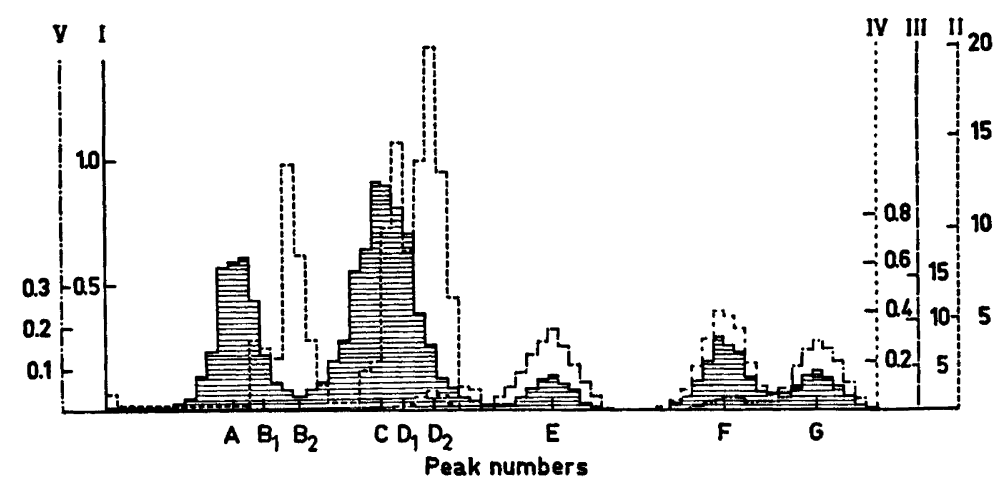

Fig. 7. Analysis of the heterogeneity of Pronase-P due to molecular size by separation of $1 \mathrm{mg}$ on a $2.5 \times 90 \mathrm{~cm}$ Sephadex G-75 Superfine bed. The separated components were identified by their enzymatic activities towards casein at pH 7.5 and 10, LNA, BAME and GPNA. The amount of activity found is calculated as optical density per $\mathrm{ml}$ eluate and hour. I, Caseinolytic activity (pH 7.5) $\mathrm{OD}_{280} \mathrm{~nm} / \mathrm{h} \mathrm{ml}$ eluate; II, LNA activity $\mathrm{OD}_{560} \mathrm{~nm} / \mathrm{h} \mathrm{ml}$ eluate; III, BAME activity $\mathrm{OD}_{253} \mathrm{~nm} / \mathrm{h} \mathrm{ml}$ eluate; IV, caseinolytic activity $(\mathrm{pH} 10) \mathrm{OD}_{280} \mathrm{~nm} / \mathrm{h}$ ml eluate; V, GPNA activity $\mathrm{OD}_{410} \mathrm{~nm} / \mathrm{h} \mathrm{ml}$ eluate. Roman numerals refer to the various enzymatic activities.

shown in Fig. 6 each component was active towards both casein at $\mathrm{pH} \mathbf{7 . 5}$ and collagenase substrate A. Consequently no indications were obtained for the presence of any zinc-free components in peak $\mathrm{A}$ or $\mathrm{C}$.

Since a considerable loss in neutral proteinase activity was reported when high concentrations of Pronase $(80 \mathrm{mg} / \mathrm{ml})$ were separated on gel chromatography ${ }^{13}$ and much more stable conditions were obtained at lower concentrations $(1.5 \mathrm{mg} / \mathrm{ml})$, it was also of interest to investigate if a less pronounced heterogeneity might occur at low enzyme concentrations. Thus a separation on a $2.5 \times 90 \mathrm{~cm}$ Sephadex G-75 Superfine bed was performed purely for analytical purposes (Fig. 7). Considering the improved resolution, which could be expected at this low sample load (and demonstrated by the separation results obtained for the leucine aminopeptidases), peak A was eluted less heterogeneous than in the $80 \mathrm{mg}$ separations. The board elution profile of peak $C$, however, indicated that this material was heterogeneous even after separation at these more stable conditions. Consequently it was concluded that the poor stability of the zinc endopeptidases in Pronase during the gel chromatography separations ${ }^{13}$ could not explain the observed heterogeneity. This seemed to be the result of unstable conditions during the fermentation and isolation of Pronase.
Since peaks $\mathrm{A}$ and $\mathrm{C}$ were distinctly separated and no intermediate sized components were found, it was, however, considered likely that the components in each of the peaks represented genuine endopeptidases produced by the actinomycete. The molecular weights of these two endopeptidases would thus be 50000 and 28000 dalton, respectively. Their content of zinc calculated per mol of enzyme also differed with a factor of about two. The possibility that the larger endopeptidase is a dimer of the smaller one can thus not be excluded. In that case the Kl Strain of Streptomyces griseus would only have produced one zinc endopeptidase. Further investigations are in progress to examine the identity of the zinc endopeptidases in Pronase.

Zinc aminopeptidases. The aminopeptidases in Pronase are in this investigation found to contain approximately one zinc atom per mol enzyme assuming an $\varepsilon(1 \%, 1 \mathrm{~cm})$ at $280 \mathrm{~nm}$ of 10. Furtheron it is shown that zinc is essential for the enzymatic activity and that the zinc ion can be reversibly removed from the aminopeptidases in a medium containing $30 \mathrm{mM}$ $\mathrm{Ca}^{2+}$. It is thus concluded that zinc is the original prosthetic metal ion of the aminopeptidases. Recently, however, Vosbeck et al. ${ }^{\circ}$ found calcium or strontium "as the preferred metal ion" of two aminopeptidases isolated 
from Pronase. By dialysis of Pronase against different metal ions calcium was earlier ${ }^{10}$ shown to be essential for the aminopeptidase activity. Calcium as well as zinc thus seems to be essential for the activity of the amino. peptidases in Pronase. It is, however, most likely that calcium plays a different role from that of zinc, and in analogy to the findings on thermolysin, ${ }^{12,20}$ another zinc- and calciumdependent proteinase, it is assumed that the calcium ions act as stabilizers, contributing to a stable and enzymatically active tertiary structure of the enzyme molecules by formation of internal salt linkages between carboxyl groups present in different parts of their polypeptide chains. The results on thermolysine also showed that this enzyme is rapidly autolyzed in calcium-free solutions. This gives a possible explanation to the "inhibitory" effect of $\mathrm{Zn}^{2+}$ noted by Narahashi and Yanagita ${ }^{10}$ for the aminopeptidases in Pronase, and it is most likely that the aminopeptidases in Pronase are calcium-stabilized zinc enzymes.

The aminopeptidases in Pronase were on gel chromatography eluted in two different peaks (B and D). Peak B was not completely separated from peak $A$ and thus pure aminopeptidase activity is only obtained in the later part of peak B. In the case of peak $D$ the alkaline proteinase (Band 9) as well as the carboxypeptidase (Band 5) are eluted together with the aminopeptidase activity, and no part of the peak contained pure aminopeptidase activity.

From the molecular weights estimated for the components in peak $B$ and $D, 37000$ and 25000 dalton respectively, ${ }^{13}$ and the absence of LNA-active components with intermediate molecular weights, it is most likely that at least two different zinc aminopeptidases are produced by the actinomycete.

A considerable heterogeneity was, however, observed within both peak $B$ and $D$ and 4-6 components with LNA-activity were found by analytical gel chromatography (Fig. 7), and gel electrophoresis (Fig. 6). No major differences in functional properties were, however, indicated between these components $(4,6,13)$, and at this stage of investigation they are assumed to be products of limited proteolysis of the aminopeptidases originally produced by the actinomycete. The favourable stability of the aminopeptidases during the course of separation ${ }^{18}$ also indicates that this limited proteolysis has occurred during the fermentation or isolation procedure of Pronase. It is thus uncertain to which extent the zinc aminopeptidases present in Pronase are identical to the ones originally produced by the actinomycete.

Carboxypeptidases. The carboxypeptidases in peak $\mathrm{D}$ and in the region between peak $\mathrm{D}$ and $\mathbf{E}$ could not be inhibited by either penten or EDTA in presence of $30 \mathrm{mM} \mathrm{Ca}{ }^{2+}$. In calciumfree media, however, Narahashi and Yanagita ${ }^{10}$ observed inactivation of the CBZ-gly-leu activity by EDTA. It thus seems likely that also the components with carboxypeptidase activity in Pronase need calcium ions as stabilizers of their tertiary structure and the observed heterogeneity is probably due to limited proteolysis. Thus it is likely that only one carboxypeptidase is produced by the Kl Strain of Streptomyces griseus.

The nature of the active site of this carboxy peptidase could, however, not be revealed by inhibition experiments. In other carboxypeptidases with similar properties, ${ }^{22}$ however, zinc was found to be so firmly bound so it could not be released even by prolonged dialysis against strong chelating agents. It can thus not be excluded that also the carboxypeptidase in Pronase is a metallo enzyme. Indications for this were indirectly obtained by examination of two minor components with true carboxypeptidase activity found in peak $F$. These components were, due to their substrate specificity and the poor stability indicated for the Pronase carboxypeptidase assumed to be partly digested products of the original carboxypeptidase and they were found to contain a firmly bound zinc atom as prosthetic metal ion. It is thus proposed that the carboxypeptidase in peak $\mathbf{D}$ or the region between $\mathrm{D}$ and $\mathrm{E}$ also is a zinc enzyme.

Serine endopeptidases. Four serine endopeptidases were as expected found in Pronase. They were eluted in chromatography peaks D, E, F, and G, respectively. From recent investigations ${ }^{15,22}$ it can also be concluded that they do represent different gene products, out of which one is described as a subtilisin-like enzyme, one as a trypsin-like enzyme, while the remaining two show properties similar to both 
Table 2. The heterogeneity of Pronase in terms of components identified on gel chromatography and gel electrophoresis and the corresponding number of original enzymes produced by $S t r e p$ tomyces griseus Strain Kl.

\begin{tabular}{|c|c|c|c|c|c|}
\hline \multirow{2}{*}{$\begin{array}{l}\text { Gel chro- } \\
\text { matog- } \\
\text { raphy } \\
\text { peak }\end{array}$} & \multicolumn{4}{|c|}{$\begin{array}{l}\text { Electrophoretically separated Pronase components }{ }^{a} \text { present } \\
\text { in the various gel chromatography peaks }{ }^{b}\end{array}$} & \multirow{2}{*}{$\begin{array}{l}\text { Suggested } \\
\text { number of } \\
\text { enzymes } \\
\text { produced } \\
\text { by Strepto. } \\
\text { myces } \\
\text { griseus } \\
\text { Strain Kl }\end{array}$} \\
\hline & $\begin{array}{l}\text { Zinc endo- } \\
\text { peptidases }\end{array}$ & $\begin{array}{l}\text { Zinc amino- } \\
\text { peptidases }\end{array}$ & $\begin{array}{l}\text { Carboxy- } \\
\text { peptidase }\end{array}$ & $\begin{array}{l}\text { Serine endo- } \\
\text { peptidases }\end{array}$ & \\
\hline
\end{tabular}

\begin{tabular}{|c|c|c|c|c|c|}
\hline A & $8,9^{\prime}$ & - & - & - & 1 \\
\hline B & - & 6,7 & - & - & 1 \\
\hline $\mathbf{C}$ & $10^{\prime}, 12,13$ & - & - & - & 1 \\
\hline D & - & $10,11,12^{\prime}, 14$ & 5 & 9 & $\mathbf{3}$ \\
\hline $\mathbf{E}$ & - & - & - & 4 & 1 \\
\hline $\mathbf{F}$ & - & - & - & $1,(2)$ & 1 \\
\hline$G$ & - & - & - & 3 & 1 \\
\hline
\end{tabular}

$a$ The components are numbered as in Ref. 13. ${ }^{b}$ Each component has in case of incomplete separation between different peaks only been assigned to the peak in which its main activity is found.

chymotrypsin and elastase. Together with the main components each peak was also found to contain minor constituents. ${ }^{13}$ These minor constituents in peak $F$ were further examined and found to have a substrate specificity completely different from the main component. This further stresses the need for thorough purification control of the Pronase enzymes before detailed characterization of their properties is carried out. ${ }^{15}$

The summarized results of the heterogeneity found for the different categories of proteolytic enzymes in Pronase are given in Table 2. The assumed number of original enzymes produced by the Streptomyces griseus Strain $\mathrm{Kl}$ is 9, out of which 4 are serine enzymes and at least 4 are zinc enzymes. Further 9 zinc-depending major components are found in the particular batch of Pronase investigated. There is, however, so far no evidence indicating that these components should represent original enzymes. At this stage of investigation it is therefore most relevant to classify them as products of limited proteolysis.

Acknowledgements. I wish to express my gratitude to Professor G. Ehrensvärd for his continuous interest in this work. I also like to thank Mrs. Y. Skoog and Miss A.-M. Dahl for their most skilful technical assistance. Thanks are also due to Mrs. G. Norén and K. Löfqvist for their assistance in editing the manuscript. I am also indebted to Drs. C.-A. Bauer and B. Jergil for valuable advice and discussions.

\section{REFERENCES}

1. Nomoto, M. and Narahashi, Y. J. Biochem. (Tokyo) 46 (1959) 653.

2. Narahashi, Y., Shibuya, K. and Yanagita, M. J. Biochem. (Tokyo) 64 (1968) 427.

3. Trop, M. and Birk, Y. Biochem. J. 116 (1970) 19.

4. Löfqvist, B. and Sjöberg, L.-B. Acta Chem. Scand. 25 (1971) 1663.

5. Wählby, S., Zetterqvist, Ö. and Engström, L. Acta Chem. Scand. 19 (1965) 1247.

6. Vosbeck, K. D., Chow, K.-F. and Awad, W. M. J. Biol. Chem. 248 (1973) 6029.

7. Awad, W. M., Soto, A. R., Siegel, S., Skiba, W. E., Bernström, G. G. and Ochoa, M. S. J. Biol. Chem. 247 (1972) 4144.

8. Wählby, S. and Engström, L. Biochim. Biophys. Acta 151 (1968) 402.

9. Jurášek, L., Fackre, D. and Smillie, L. B. Biochem. Biophys. Res. Commun. 37 (1969) 99.

10. Narahashi, Y. and Yanagita, M. J. Biochem. (Tokyo) 62 (1967) 633.

11. Nomoto, M., Narahashi, Y. and Murakami, M. J. Biochem. (Tokyo) 48 (1960) 906.

12. Feder, J., Garrett, L. R. and Wildi, B. S. Biochemistry 24 (1971) 4552.

13. Löfqvist, B. and Klevhag, J. E. Acta Chem. Scand. $B 28$ (1974) 1003.

14. Erlanger, B., Edel, F. and Cooper, A. Arch. Biochem. Biophys. 115 (1966) 206.

Acta Chem. Scand. B 28 (1974) No. 9 
15. Bauer, C.-A. and Löfqvist, B. Acta Chem. Scand. 27 (1973) 3147.

16. Wünsch, E. and Heidrich, H. G. HoppeSeyler's Z. Physiol. Chem. 333 (1963) 149.

17. Yemm, E. and Cocking, E. Analyst 80 (1955) 209.

18. Hiramatsu, A. and Ouchi, T. J. Biochem. (Tokyo) 71 (1972) 767.

19. Prescott, J. M., Wilkes, S. H., Wagner, F. W. and Wilson, K. J. Biol. Chem. 246 (1971) 1756.

20. Matthews, B. W., Colman, P. M., Jansonius, J. N., Titani, K., Walsh, K. A. and Neurath, H. Nature (London) New Biol. 238 (1972) 41.

21. Hofsten, B. v., Nässén-Puu, G. and Drevin, I. FEBS Lett. (1974). In press.

22. Siegel, S. and Awad, W. M. J. Biol. Chem. 248 (1973) 3233.

Received April 30, 1974. 